\title{
Barriers associated with emergency medical service activation in patients with ST-segment elevation acute coronary syndromes
}

\author{
Enrico Baldi ${ }^{1,2}$ (1) Rita Camporotondo ${ }^{2} \cdot$ Massimiliano Gnecchi $^{1,2} \cdot$ Rossana Totaro $^{2} \cdot$ Stefania Guida $^{2}$. \\ Ilaria Costantino ${ }^{2}$. Alessandra Repetto ${ }^{3} \cdot$ Simone Savastano $^{3} \cdot$ Maria Clara Sacchi $^{2} \cdot$ Carola Bollato $^{4}$.

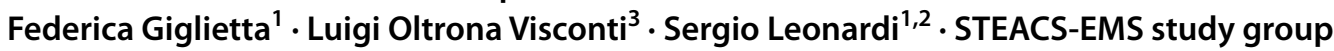

Received: 4 April 2021 / Accepted: 13 November 2021 / Published online: 26 November 2021

(c) Società Italiana di Medicina Interna (SIMI) 2021

\begin{abstract}
Many ST-segment elevation acute coronary syndrome (STEACS) patients fail to activate the Emergency Medical System (EMS), with possible dramatic consequences. Prior studies focusing on barriers to EMS activation included patients with any acute coronary syndrome (ACS) without representation of southern European populations. We aimed to investigate the barriers to EMS call for patients diagnosed for STEACS in Italy. A prospective, single-center, survey administered to all patients treated with primary percutaneous coronary intervention for STEACS in a tertiary hospital in northern Italy from 01/06/2018 to 31/05/2020. The questionnaire was filled out by 293 patients. Of these, 191 (65.2\%) activated the EMS after symptoms onset. The main reasons for failing to contact EMS were the perception that the symptoms were unrelated to an important health problem (45.5\%) and that a private vehicle is faster than EMS to reach the hospital (34.7\%). Patients who called a private doctor after symptoms onset did not call EMS more frequently than those who did not and $30 \%$ of the patients who did not call the EMS would still act in the same way if a new episode occurred. Previous history of cardiovascular disease was the only predictor of EMS call. Information campaigns are urgently needed to increase EMS activation in case of suspected STEACS and should be primary focused on patients without cardiovascular history, on the misperception that a private vehicle is faster than EMS activation, and on the fact that cardiac arrest occurs early and may be prevented by EMS activation.
\end{abstract}

Keywords STEACS $\cdot$ Emergency Medical System $\cdot$ Barriers $\cdot$ Primary percutaneous coronary intervention

The members of the STEACS-E M S study group are mentioned in the Acknowledgements section.

Enrico Baldi

enrico.baldi@unipv.it

1 Department of Molecular Medicine, Section of Cardiology, c/o Fondazione IRCCS Policlinico San Matteo, University of Pavia, Viale Golgi 19, 27100 Pavia, Italy

2 Cardiac Intensive Care Unit, Arrhythmia and Electrophysiology and Experimental Cardiology, Fondazione IRCCS Policlinico San Matteo, Pavia, Italy

3 Division of Cardiology, Fondazione IRCCS Policlinico San Matteo, Pavia, Italy

4 Anestesia E Rianimazione II Cardiopolmonare, Fondazione IRCCS Policlinico San Matteo, Pavia, Italy

\section{Introduction}

ST-segment acute coronary syndrome (STEACS) is a common and life-threatening condition. Its incidence ranges from 43 to 144 per 100.000 per year in Europe [1]. The most effective treatment is timely reperfusion by primary percutaneous coronary intervention (pPCI) [2, 3]. Both European and American guidelines recommend that patients with symptoms suspected for STEACS should promptly contact the Emergency Medical System (EMS) and wait to be transferred to the hospital by the EMS $[4,5]$. This is of paramount importance considering that ventricular tachycardia or ventricular fibrillation occur in about $10-20 \%$ of the patients suffering from acute myocardial ischemia [6-8] and that these malignant ventricular arrhythmias occur very early $(<1 \mathrm{~h})$ after symptoms onset in $10 \%$ of the patients [9]. Ambulance system has a critical role in the early management of STEACS patients and acts to enhance early initial 
diagnosis, triage, and treatment. Activating EMS instead of going to the hospital by themselves has several beneficial effects.

Nevertheless, a large proportion of the patients with STEACS are still self-transporting themselves to the hospital, with important variations depending on the geographical area [10-21]. The increase in the proportion of patients activating the EMS has been modest over the last two decades [19]. Therefore, identify barriers to EMS call is crucial to organize awareness campaign aiming to increase the percentage of patients calling EMS in case of symptoms suspected for STEACS.

However, the studies carried out so far included all the spectrum of patients with ACS, with or without ST elevation, but a difference in the percentage of patients calling EMS has been highlighted according to the different ACS type [10, 17]. Moreover, most studies have been conducted in the United States [15, 16], Australia [11, 17], Arabic [20] and eastern countries [14, 18], whilst, regarding Europe, only data from northern countries (Sweden [10, 13, 19, 21] and Ireland [12]) are available. This is potentially relevant, considering that barriers to EMS call have been demonstrated to be affected by important socio-demographic and racial factors [22]. The aim of our study was to investigate the barriers to EMS call for patients diagnosed for STEACS in a population coming from southern Europe.

\section{Methods}

\section{Study type and population}

We conducted a prospective, single-center study, including all the patients treated with pPCI for a STEACS in a tertiary hospital in northern Italy (Fondazione IRCCS Policlinico San Matteo, Pavia, Italy) from June 1st, 2018 to May 31st, 2020. All the patients transferred to the Cardiac Intensive Care Unit (CICU) after pPCI were asked to fill out a survey (Supplementary Appendix 1), which was divided in two parts. The first part concerned the socio-demographic characteristics of the participants, his/her medical history, the type of symptoms and information regarding the situation when the symptoms occurred and if he/she called the EMS or has gone to the hospital with a private vehicle. We defined the time to first medical contact as the minutes from symptoms onset to the EMS call for those patients who called the EMS and the time from symptoms onset to hospital arrival for those who did not call EMS. The second part, dedicated only to the patients who did not call the EMS, concerned how the patients reached the hospital, the motivations for that choice and, if that situation occurred again, if his/her behavior would be different.
We excluded patients with out-of-hospital cardiac arrest (OHCA), as this event could lead unreliable questionnaire responses, those admitted to the general ICU because of a poor neurological status or clinical situation who required intubation, those who were unable to sign the informed consent, those non-Italian speaking and those who refused to participate.

The study was designed within a broader initiative, the clinical governance program in patients with ACS, [23] a quality improvement initiative closely integrated with clinical care which aims to promote quality measurement and improvement, better understanding of the disease process of care, scientific discovery, as so to ultimately improve the prognosis of patients with ACS. It was approved by the Ethics Committee of the Fondazione IRCCS Policlinico San Matteo and all the patients provided informed consent for this specific study.

\section{Hospital and EMS setting}

Fondazione IRCCS Policlinico San Matteo hospital is a major tertiary teaching center that offers percutaneous coronary intervention-mediated reperfusion therapy $24 \mathrm{~h}$ per day for 7 days per week (hub center). It is the only hub center of the Province of Pavia (550.000 inhabitants in northern Italy), which is covered by the Emergency Medical System of the Lombardia Region (Agenzia Regionale Emergenza Urgenza-AREU), whose organization has been already described [26]. In case of suspected ACS, both the basic life support—defibrillation (BLS-D)-trained personnel and the advanced life support (ALS)-trained personnel, acquire a 12-lead electrocardiogram (ECG) which is sent instantly to the dispatch center. All the ECG acquired in the Province of Pavia deemed suspected for ACS by the physician of the dispatch center, are transmitted to the CICU of the Fondazione IRCCS Policlinico San Matteo for consultation by the cardiologist. In case of confirmed STEACS, the patient is directly to the available catheterization laboratory at the nearest PCI-center.

\section{Statistical analysis and sample size}

Categorical variables are given as number (percentage) and were compared using the Chi-square test. Continuous variables were tested for normality with the D'Agostino-Pearson test. Normally distributed continuous variables are given as mean $\pm \mathrm{SD}$ and were compared with the Student $t$ test. Non-normally distributed continuous variables are given as median $(95 \%$ confidence interval $[\mathrm{CI}])$ and were compared with the Mann-Whitney test if independent or the Wilcoxon test in case of dependent variables. $P$ value $<0.05$ was considered significant. We performed a logistic regression analysis to identify predictors of EMS activation according to the 
literature $[10,12,13,16,20]$. All data were anonymized and analyzed with MedCalc Version 19.6 (MedCalc Software bvba) and $\mathrm{R}$ version 4.0.4 ( $\mathrm{R}$ foundation). The study was powered on the primary subgroup of interest, patients with STEACS who did not call EMS, assuming an appropriateness of $43 \%$ in this patient population based on historical data. Using a normal approximation to the binomial distribution for this proportion, a population of 276 patients with STEACS were needed to obtain a 95\% CI between 38 and $52 \%$ for appropriateness. Sample size was estimated using www.sample-size.net.

\section{Results}

The patients admitted to our hospital for STEACS during the study period were 545: 338 (62\%) of them called the EMS and were transferred to our hospital (EMS-activation group), whilst the others went to the hospital by themselves (self-transportation group). Of these 252 were excluded (36 with OHCA, 28 were not admitted to the CICU because of a poor neurological status or clinical situation who required intubation, 42 were unable to sign the informed consent, 31 were non-Italian speaking and the other 115 refused to participate). Among the 36 patients who experienced an out-ofhospital cardiac arrest, 22 were witnessed by the EMS, with a median time from EMS call to cardiac arrest of $33 \mathrm{~min}$ [IQR, 28-48.5].

The questionnaire was filled out by 293 patients. Among those, 191 (65.2\%) called the EMS after symptoms onset (Supplementary Fig. 1). The questionnaire was administered in median 1 day [IQR, 0-2] after the hospitalization.

\section{Socio-demographic characteristics and previous medical history}

The majority of the participants were males (74\%), married (70.4\%), with a high-school degree (38.4\%) and with a median age of 62 years. No differences in sex, age, civil status and level of education were observed comparing the EMS-activation and the self-transportation groups. Hypertension, familiar history of cardiovascular disease and smoking were present in about half of the participants and the median number of risk factors for each subject was 2 . However, the cardiovascular risk factors type, and number were similar between the two groups. A previous cardiovascular disease was reported by $20.3 \%$ of the patients and this percentage was higher in the EMS-activation group (Table 1). Most of the participants have no previous medical training (73.2\%), 22.7\% participated at least to a first aid course and $4.2 \%$ were nurses or medical doctors, with no difference between the two groups. Chest pain as a possible symptom related to a cardiovascular attack was known by most of the respondents (89\%), and left arm pain/shake by the half of them, whilst the other possible signs and symptoms were unknown to the majority of the participants. Comparing the two groups, only dyspnea has been more widely recognized as a possible cardiovascular symptom in the EMS-activation group.

\section{Type of symptoms, the situation when the symptoms occurred and how the patients reached the hospital}

The median time to first medical contact was $60 \mathrm{~min}$, and it was significantly higher in the self-transportation group (Table 2). Regarding signs and symptoms experienced by the patients, chest pain was reported by $79.2 \%$ of the patients, sweating by $50.5 \%$, chest pressure by $36 \%$, left arm pain/ shake by $33.9 \%$, whilst the other signs/symptoms were reported by less of one third. Comparing the two groups, only sweating and dizziness were reported significantly more in the EMS-activation group, whilst the other signs/ symptoms were similarly reported in the two groups. The episode was the first one in $76.2 \%$ of the respondents and the median visual analog scale (VAS) for pain was $8 / 10$, without differences between the two groups. Most of the patients were at home when the symptoms occurred (83.4\%) and another person was present in $81.8 \%$ of the cases (a relative in $67.8 \%$ ). Once symptoms have begun, only $6.7 \%$ of the respondents called the EMS or went to the hospital as first move, whilst 93.3\% first alerted someone else: a doctor in $6.7 \%$ of the cases, with no differences between the two groups. Regarding the reasons for delaying the medical contact, the hope of either a spontaneous symptoms relief or a non-cardiac cause of symptoms were the most reported (61.6\% and $37.9 \%$, respectively), without any difference between the two groups.

\section{Patients who did not call the EMS}

Among the 102 patients in the self-transportation group, $21.8 \%$ drove himself the car to the hospital, $2 \%$ used a taxi and $1 \%$ went by foot, whilst in $75.2 \%$ a relative or friend drove the car. The patients went to a spoke-center without PCI capability in $51 \%$ of the cases. Patients were prevented to call the EMS mainly because they thought that they did not have a major health problem $(45.5 \%)$ or that the car would be faster than the ambulance $(34.7 \%)$ or because they did not consider the possibility of calling EMS (11.9\%). Other minor motivations were that he/she was already in the car (7.9\%), the desire to choose the hospital (5\%), the violation of privacy by ambulance sirens $(2 \%)$, the desire not to disturb (3\%) and previous negative experiences with EMS (1\%). As many as 30\% of the respondents answered that he/she would not call the EMS again in case of further 
Table 1 Socio-demographic characteristics of the participants and their medical history in the overall population and comparison between the two groups

\begin{tabular}{|c|c|c|c|c|}
\hline Variable & Overall & EMS activation & Self-transported & $p$ \\
\hline Males, $n(\%)$ & $211(74)$ & $139(75.5)$ & $72(72.7)$ & 0.60 \\
\hline Age, years [IQR] & $62[55-71]$ & $62[55-71]$ & $61[55-70]$ & 0.47 \\
\hline \multicolumn{4}{|l|}{ Civil status, $n(\%)$} & \multirow[t]{6}{*}{0.51} \\
\hline Single & $26(8.9)$ & $18(9.6)$ & $8(7.8)$ & \\
\hline Married & $205(70.4)$ & $128(68.4)$ & $75(73.5)$ & \\
\hline Divorced & $27(9.3)$ & $20(10.7)$ & $7(6.9)$ & \\
\hline Widowed & $17(5.8)$ & $9(4.8)$ & $8(7.8)$ & \\
\hline Other & $16(5.5)$ & $12(6.4)$ & $4(3.9)$ & \\
\hline \multicolumn{4}{|l|}{ Level of education, $n(\%)$} & \multirow[t]{5}{*}{0.64} \\
\hline Primary School & $56(19.2)$ & $35(18.5)$ & $20(19.8)$ & \\
\hline Secondary School & $97(33.2)$ & $59(31.2)$ & $37(36.6)$ & \\
\hline High-school & $112(38.4)$ & $78(41.3)$ & $34(33.7)$ & \\
\hline Degree & $27(9.2)$ & $17(9)$ & $10(9.9)$ & \\
\hline \multicolumn{5}{|l|}{ CV risk factor, $n(\%)$} \\
\hline Diabetes mellitus & $39(14.7)$ & $23(13.5)$ & $16(17)$ & 0.44 \\
\hline Hypertension & $124(46.6)$ & $73(42.9)$ & $50(53.2)$ & 0.11 \\
\hline Dyslipidemia & 37 (13.9) & $25(14.7)$ & $12(12.8)$ & 0.66 \\
\hline Familiar history & $115(43.2)$ & $71(41.8)$ & $43(45.7)$ & 0.53 \\
\hline Smoking & $147(55.3)$ & $98(57.6)$ & $48(51.1)$ & 0.30 \\
\hline Number of CV risk factors & $2[1,2]$ & $2[1,2]$ & $2[1,2]$ & 0.50 \\
\hline Previous CV disease, $n(\%)$ & $59(20.3)$ & $45(24.1)$ & $14(13.7)$ & 0.04 \\
\hline \multicolumn{4}{|c|}{ Previous first aid teaching, $n(\%)$} & \multirow[t]{5}{*}{0.31} \\
\hline No & $213(73.2)$ & $138(73.8)$ & 73 (71.6) & \\
\hline First aid only & $66(22.7)$ & $42(22.5)$ & $24(23.5)$ & \\
\hline Nurse & $6(2.1)$ & $5(2.7)$ & $1(1)$ & \\
\hline Medical Doctor & $6(2.1)$ & $2(1.1)$ & $4(3.9)$ & \\
\hline \multicolumn{5}{|c|}{ Signs/symptoms thought to be related to a CV attack, $n(\%)$} \\
\hline Chest pain & $252(89)$ & $163(88.1)$ & $87(90.6)$ & 0.53 \\
\hline Stomach Burning & $37(13.1)$ & $25(13.5)$ & $12(12.5)$ & 0.81 \\
\hline Left arm pain/shake & $152(53.7)$ & $94(50.8)$ & $57(59.4)$ & 0.17 \\
\hline Chest pressure & $90(31.8)$ & $57(30.8)$ & $32(33.3)$ & 0.67 \\
\hline Dyspnea & $72(25.4)$ & $55(29.7)$ & $16(16.7)$ & 0.02 \\
\hline Asthenia & $42(14.8)$ & $27(14.6)$ & $15(15.6)$ & 0.82 \\
\hline Sweating & $64(22.6)$ & $46(24.9)$ & $18(18.8)$ & 0.25 \\
\hline Nausea, vomiting & $44(15.5)$ & $28(15.1)$ & $16(16.7)$ & 0.74 \\
\hline Dizziness & $22(7.8)$ & $17(9.2)$ & $5(5.2)$ & 0.24 \\
\hline
\end{tabular}

$C V$ cardiovascular

episodes and the main reasons were that they think to be faster than EMS (57.1\%) and to live close to the hospital (17.9\%) (Table 3).

\section{Predictors of calling the EMS}

Only prior history of cardiovascular disease has been demonstrated to be a predictor of calling the EMS in case of symptoms suspected for STEACS, whilst none of the other tested predictors resulted to be significant associated with EMS call. (Fig. 1 and Supplementary Table 1).

\section{Discussion}

We first explored barriers to EMS activation in patients with STEACS in a population coming from southern Europe. The study confirms that one third of patients did not activate the EMS and decided to go to the hospital by themselves. Patients' and event's characteristics seem to be similar comparing those who called the EMS and those who did not, pointing out the need of information campaign targeted to the whole population, especially to those without an history of cardiovascular disease. These campaigns should stress both the concept that the EMS is faster than private vehicles 
Table 2 Type of symptoms and information regarding the situation when the symptoms occurred in the overall population and comparison between the two groups

\begin{tabular}{|c|c|c|c|c|}
\hline Variable & Overall & EMS activation & Self-transported & $P$ \\
\hline Time to first medical contact, mins [IQR] & $60[16-214]$ & $35[15-120]$ & $180[60-420]$ & $<0.001$ \\
\hline \multicolumn{5}{|l|}{ Signs/symptoms experienced, $n(\%)$} \\
\hline Chest pain & $229(79.2)$ & 149 (79.7) & $78(78)$ & 0.74 \\
\hline Stomach burning & $41(14.2)$ & $26(13.9)$ & $14(14)$ & 0.98 \\
\hline Left arm pain/shake & $98(33.9)$ & $60(32.1)$ & $38(38)$ & 0.31 \\
\hline Chest pressure & $104(36)$ & $64(34.2)$ & $40(40)$ & 0.33 \\
\hline Breathlessness & $75(26)$ & $54(28.9)$ & $20(20)$ & 0.10 \\
\hline Tiredness & $68(23.5)$ & $40(21.4)$ & $27(27)$ & 0.28 \\
\hline Sweating & $146(50.5)$ & $105(56.1)$ & $40(40)$ & $<0.01$ \\
\hline Nausea, vomiting & $76(26.3)$ & $53(28.3)$ & $22(22)$ & 0.25 \\
\hline Dizziness & $36(12.5)$ & $28(15)$ & $7(7)$ & 0.049 \\
\hline Right arm & $14(4.8)$ & $8(4.3)$ & $6(6)$ & 0.52 \\
\hline Back pain & $15(5.2)$ & $5(2.7)$ & $7(7)$ & 0.08 \\
\hline Teeth, jaw & $12(4.2)$ & $8(4.3)$ & $7(7)$ & 0.32 \\
\hline Number typical symptoms, $n(\%)$ & $1[1,2]$ & $1[1,2]$ & $1.5[1,2]$ & 0.21 \\
\hline Number atypical symptoms, $n(\%)$ & $1[1,2]$ & $1[1,2]$ & $1[0.5-2]$ & 0.08 \\
\hline First time that patient suffered these symptoms, $n(\%)$ & $221(76.2)$ & $138(73.4)$ & $81(81)$ & 0.15 \\
\hline VAS Pain, median [IQR] & $8[6-9]$ & $8[6-9]$ & $8[6-9]$ & 0.17 \\
\hline \multicolumn{4}{|l|}{ Location, $n(\%)$} & 0.40 \\
\hline Home & $242(83.4)$ & $153(81.4)$ & $87(87)$ & \\
\hline Work & $17(5.9)$ & $11(5.9)$ & $6(6)$ & \\
\hline By relatives/friends & $5(1.7)$ & $2(1.1)$ & $3(3)$ & \\
\hline Public place & $9(3.1)$ & $8(4.3)$ & $1(1)$ & \\
\hline In a vehicle & $7(2.4)$ & $6(3.2)$ & $1(1)$ & \\
\hline Sporting Place & $6(2.1)$ & $5(2.7)$ & $1(1)$ & \\
\hline Other & $4(1.4)$ & $3(1.6)$ & $1(1)$ & \\
\hline \multicolumn{4}{|l|}{ Who was present when the patient had symptoms, $n(\%)$} & 0.37 \\
\hline None & $52(18.2)$ & $32(17.1)$ & $20(20.2)$ & \\
\hline Relative & $194(67.8)$ & $124(66.3)$ & $70(70.7)$ & \\
\hline Friend/Colleague & $21(7.3)$ & $16(8.6)$ & $5(5.1)$ & \\
\hline Other & $19(6.6)$ & $15(8)$ & $4(4)$ & \\
\hline \multicolumn{4}{|c|}{ Who alerted first before call EMS or go to the hospital, $n(\%)$} & 0.30 \\
\hline None & $19(6.7)$ & $13(7)$ & $6(6.2)$ & \\
\hline Relative & $222(78.4)$ & $143(76.9)$ & $79(81.4)$ & \\
\hline Friend/colleague & $23(8.1)$ & $19(10.2)$ & $4(4.1)$ & \\
\hline Doctor & $19(6.7)$ & $11(5.9)$ & $8(8.2)$ & \\
\hline \multicolumn{4}{|l|}{ Who decided for the need of advanced medical help, $n(\%)$} & 0.64 \\
\hline Patients himself & $78(27.7)$ & $54(29.3)$ & $24(24.5)$ & \\
\hline Relative & $165(58.5)$ & $105(57.1)$ & $60(61.2)$ & \\
\hline Friend/Colleague & $15(5.3)$ & $11(6)$ & $4(4.1)$ & \\
\hline Doctor & $24(8.5)$ & $14(7.6)$ & $10(10.2)$ & \\
\hline \multicolumn{5}{|l|}{ Waited to ask for advanced medical help because, $n(\%)^{\mathrm{a}}$} \\
\hline Thought the pain would go away by itself & $77(61.6)$ & $47(63.5)$ & $30(58.8)$ & 0.59 \\
\hline Not want to disturb other people & $12(9.6)$ & $8(10.8)$ & $4(7.8)$ & 0.58 \\
\hline Thought they were not important symptoms & $24(19.2)$ & $16(21.6)$ & $8(15.7)$ & 0.41 \\
\hline Thought it was not a heart problem & $47(37.6)$ & $24(32.4)$ & $23(45.1)$ & 0.15 \\
\hline Symptoms were inconstant & $21(16.8)$ & $13(17.6)$ & $8(15.7)$ & 0.78 \\
\hline Previous negative experiences with hospitals & $1(0.8)$ & $0(0)$ & $1(2)$ & 0.23 \\
\hline Wish to consult with my General Practitioner first & $5(4)$ & $3(4.1)$ & $2(3.9)$ & 0.97 \\
\hline
\end{tabular}


Table 2 (continued)

\begin{tabular}{|c|c|c|c|c|}
\hline Variable & Overall & EMS activation & Self-transported & $P$ \\
\hline Fear & $9(7.2)$ & $5(6.8)$ & $4(7.8)$ & 0.81 \\
\hline Embarrassment & $2(1.6)$ & $2(2.7)$ & $0(0)$ & 0.24 \\
\hline \multicolumn{5}{|c|}{ How reached the hospital, $n(\%)$} \\
\hline Calling EMS & $189(64.9)$ & - & - & \\
\hline By private vehicle & $102(35.1)$ & - & - & \\
\hline \multicolumn{5}{|c|}{ Time from symptoms to EMS call/hospital arrival, $n(\%)$} \\
\hline$>1 \mathrm{~h}$ & $113(48.1)$ & $65(38.7)$ & $48(72.7)$ & $<0.001$ \\
\hline$>2 \mathrm{~h}$ & $81(34.5)$ & $40(23.8)$ & $41(62.1)$ & $<0.001$ \\
\hline
\end{tabular}

$V A S$ visual analog scale

${ }^{\mathrm{a}}$ Only in those who waited more than $30 \mathrm{~min}$

Table 3 Information regarding how the patients has gone to the hospital, the motivations for that choice and the behavior if that situation occur again in the self-transported group

\begin{tabular}{lc}
\hline Variable & Overall \\
\hline How reached the hospital, $n(\%)$ & $22(21.8)$ \\
Drove himself & $76(75.2)$ \\
Drove a relative/friend & $2(2)$ \\
Taxi & $1(1)$ \\
On foot & \\
Why did not called the EMS?, $n(\%)$ & $12(11.9)$ \\
Not thought about it & $46(45.5)$ \\
Thought not an important health problem & $35(34.7)$ \\
Car is faster & $2(2)$ \\
Ambulance sirens violate my privacy & $5(5)$ \\
Wanted to choose the hospital & $1(1)$ \\
For negative experiences with personal or family/ & \\
friends' & $0(0)$ \\
Not known what number to dial to call EMS & $8(7.9)$ \\
Was already in the car & $3(3)$ \\
Did not want to disturb & $0(0)$ \\
Did not think that the EMS could help & $4(3.9)$ \\
Other & \\
Which hospital & $50(49)$ \\
Hub-center & $52(51)$ \\
Spoke-center & \\
What would the patient do if it happens again & $69(69.7)$ \\
Call EMS & $30(30.3)$ \\
Again by private vehicle & \\
Why again with a private vehicle & \\
Near to the hospital & \\
Faster the EMS & \\
\hline
\end{tabular}

to direct the patient to the right hospital and the possible symptoms in case of heart attack, which seem to be the most neglected issues by patients who did not call the EMS. Two strengths of our paper are that, differently from prior studies, we focused on the barriers to EMS activation including only patients with STEACS and we considered a population coming from a region not included in other studies.

EMS has consistently demonstrated to improve STEACS patients' outcome [25, 26] through different actions: prehospital diagnosis acquiring early electrocardiogram (ECG) [25]; directing patients immediately to a PCI-capable-hospital bypassing the emergency department and bringing them straight to the catheterization laboratory saving time [26]; starting pre-hospital treatment and solving quickly possible arrhythmic complications that could be lethal if occurred during non-EMS transport [27].

\section{EMS activation and reasons for not calling}

About two third of the STEACS patients who answered to our study decided to call the EMS. This percentage seems definitely higher compared to data coming from Arabic and Eastern countries, where it is around 1-23\% [14, 18, 20], but also higher compared to recent northern European data $[12,13,19]$, where this percentage range from $40 \%$ in Ireland in 2016 to $50 \%$ in Sweden in 2009. This result is partially expected as our study focus exclusively on STEACS patients, whilst the previous evidence considered all ACS patients, and it has been demonstrated that STEACS compared to other ACS is a predictor for EMS call [10, 14]. This was also evident in a study from Cartledge in Australia, where $54 \%$ of all ACS called the EMS compared to $69 \%$ in a sub-analysis of only STEACS patients [17]. We believe that this is a strength of our paper, as it provides a more accurate picture of patients with STEACS, whose outcome is more likely to be negatively affected by a missed or a delayed call to EMS than patients with NSTE-ACS and UA, usually presenting milder symptoms [2, 3]. Moreover, the time to first medical contact was significantly higher in the self-transportation group, posing them at higher risk of prehospital complications and increasing the treatment delay. 

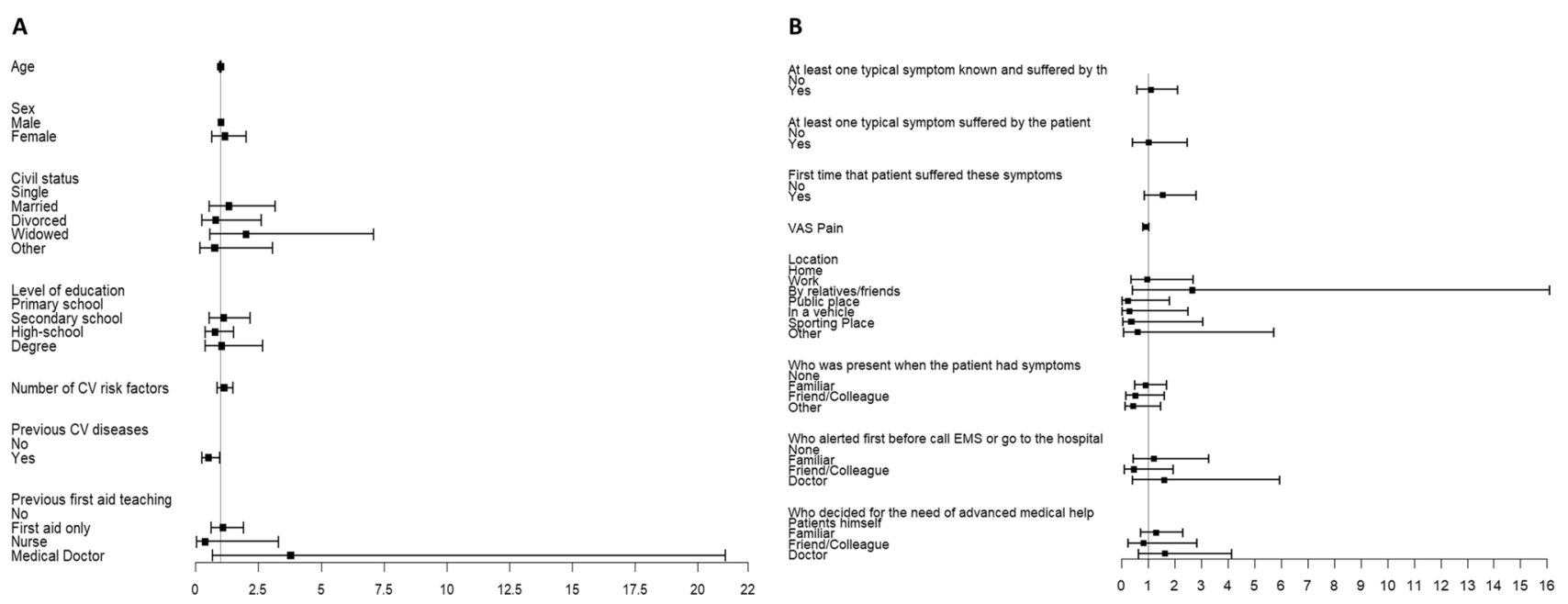

Fig. 1 Forest plot of the predictors of going to the hospital by private transport not calling EMS

Analyzing the reasons for not calling EMS, most of the patients (45.5\%) thought that the symptoms experienced were not related to an important health problem. This was one of the most reported reasons also in previous studies, both recent and less recent, coming from different part of the world [11-13, 15, 17, 18, 28]. One of the interesting elements highlighted in our study is that many patients did not know which could be the possible symptoms related to a heart attack. Whereas $90 \%$ of respondents knew that chest pain can be one of the possible symptoms, only $50 \%$ knew that a pain/shake in the left arm can be too, whilst a very low percentage of patients recognized the chest pressure, the stomach burning or the associated symptoms (i.e., dyspnea, asthenia, sweating, nausea, vomiting, dizziness) as possibly related to an acute heart disease. An information campaign focusing on which are the possible symptoms related to a heart attack can therefore probably increase the percentage of STEACS patients calling the EMS. Moreover, since it has been previously highlighted that patients recognizing their symptoms as possibly related to an heart problem seek care faster than the others [22, 29, 30], an under knowledge of possible heart attack symptoms surely delay the EMS calling.

The other relevant reason for not calling the EMS, reported by $34.7 \%$ of our respondents, is that the patients believed that a private vehicle is faster than EMS to reach the hospital. Also, this motivation was reported in the previous studies as much in the United States as in Asia, Australia and northern Europe [12, 13, 15, 17, 18]. This is one of the most important issues on which an informative campaign should focus on as about $10-20 \%$ of the treated STEACS can be complicated by an out-of-hospital cardiac arrest (OHCA) [6-8] and this is probably an underestimated value considering the incidence of OHCA worldwide, the vast majority of which are of medical etiology [31]. This is a critical point as going to the hospital with a private vehicle deprives the patient of the possibility of early treatment by EMS personnel, who can also solve quickly eventual arrhythmic complications that could be lethal if occurred during non-EMS transport [27]. Moreover, $21.8 \%$ of the patients who did not call the EMS drove himself to the hospital, with possible dramatic consequences also for other road users in case of cardiac arrest during the trip. Importantly, the median time from EMS call to OHCA for those who experienced cardiac arrest witnessed by EMS was 33 min, highlighting the importance to promptly call EMS in case of symptoms suspected for STEACS. This is even more important considering that an early treatment of OHCA allow not only to increase the patients' chance of survival, but also reduce the possibility of long-term neurologic consequences of the OHCA $[32,33]$. Furthermore, about half of the patients went to an hospital without PCI capability, and this has led to an delay in reperfusion time with impact of infarct size and long-term outcome [34].

\section{Predictors of EMS activation}

Only to have a history of cardiovascular disease seems to be associated with EMS call rather than going to the hospital by themselves. Another point worth of discussion is that both the consultation of a private doctor as first action in case of symptoms and the indication to advanced health care by a doctor were not predictors of EMS call. This evidence is unfortunately not surprising, as it was already highlighted in previous studies [11, 12,16], but it is surely alarming. ESC guidelines recommend the general practitioners, if contacted by a patient with symptoms suspected for STEACS, to alert the EMS as first task [5]. This seems not to be respected in 
our survey, increasing the risk for the patients and preventing both the early activation of the EMS system and the pre-hospital diagnosis, which is of paramount importance to reduce treatment delays and mortality $[35,36]$. Informative campaign should also be addressed to medical doctors to emphasize the importance of the activation of the EMS in case of suspected STEACS.

\section{Patients' behavior in case of a new event}

Another alarming finding which emerged from our study is that $30 \%$ of the patients who did not call the EMS would still act in the same way in case of recurrences because they believe that private vehicles are faster than EMS or because they live near a hospital. Although this kind of reply could be influenced by the short time between hospitalization and questionnaire administration, this stresses the need to aggressively inform the patients regarding the importance to early alert the EMS in case of a new episodes.

\section{Limitations}

The first limitation of our study is that there is a consistent percentage of patients admitted for STEACS who did not fill out the questionnaire. However, this is an issue common to many surveys and, moreover, the percentage of patients who did not call the EMS in those who filled out the questionnaire is similar to that of the whole population of patients admitted for STEACS in the study period. A second limitation is that we excluded patients who were admitted to general ICU and those non-Italian speaking, therefore our results may not be the same in those populations. Moreover, our study is a single-center study conducted in a tertiary hospital in northern Italy. Therefore, our results may not be extrapolated to other European regions or countries suggesting the need for multicenter studies on this topic involving different European countries. Another limitation is that the answers regarding the symptoms known to be related to a heart attack by the patient before the event could be influenced by the symptoms experienced by the patient during the event. The fourth limitation is that, regarding the time to first medical contact, we evaluated the time to EMS call and not to EMS arrival for the EMS-activation group. Moreover, the questionnaire was administered in median 1 day after the hospitalization and shorter or longer time from hospitalization to questionnaire administration could lead to slightly different results. Lastly, the study period includes the first 3 months of COVID-19 pandemic in Italy, during which a reduction in hospitalizations for myocardial infarction and an increase the late-presenting STEACS have been demonstrated [24, 37, 38]. Although this may have affected the behavior of patients with STEACS in that period we believe, considering many aspects, that this has only marginally affected our results. Indeed, both the patients enrolled in that period and the pandemic weeks represents only about $15 \%$ of the whole population and of the period study, respectively; almost all the patients' characteristics are similar before and during COVID (Supplementary Table 2); the focus of our study is not the rate of hospitalization and none of the respondents indicated COVID-19 as a reason for delaying seeking advance medical help or not calling EMS.

\section{Conclusions}

We observed that a substantial percentage of patients with symptoms suspected for STEACS preferred private vehicle rather than activating the EMS. Our results highlight the need for information campaigns targeted to both the general population and medical doctors, stressing that EMS is faster than a private vehicle to direct the patient to the right hospital and increasing the awareness of the people on the type of possible heart attack symptoms, which seem to be the most neglected issues by patients who did not call the EMS.

Supplementary Information The online version contains supplementary material available at https://doi.org/10.1007/s11739-021-02894-7.

Acknowledgements STEACS-EMS study group researchers: Valeria Crescio, Irene Raso, Andrea Demarchi, Alberto Somaschini, Stefano Cornara, Silvana De Martino, Chiara Gargiulo, Paolo Bozzini, Stefano Buratti, Michela Coccia, Federico Fortuni, Ambra Uccello, Giulia Fini, Sabato D’Amore, Davide Foglia, Marco Rolando, Arianna Grelli, Letizia Mannucci, Lucrezia Masiello, Matteo Astuti, Veronica Buia, Martina Querio Giannetto, Raniero Covi, Ciro Di Giacomo, Laura Frigerio, Francesco Moretti, Simonluca Digiacomo, Laura Pezza, Matteo Casula, Vilma Kajana, Francesca Fabris, Martina Moschella, Francesco Jeva, Claudio Montalto, Leonardo Pignalosa

Valeria Crescio, Irene Raso, Andrea Demarchi, Alberto Somaschini, Stefano Cornara, Silvana De Martino, Chiara Gargiulo, Paolo Bozzini, Stefano Buratti, Michela Coccia, Federico Fortuni, Ambra Uccello, Giulia Fini, Sabato D'Amore, Davide Foglia, Marco Rolando, Arianna Grelli, Letizia Mannucci, Lucrezia Masiello, Matteo Astuti, Veronica Buia, Martina Querio Giannetto, Raniero Covi, Ciro Di Giacomo, Laura Frigerio, Francesco Moretti, Simonluca Digiacomo, Laura Pezza, Matteo Casula, Vilma Kajana, Francesca Fabris, Martina Moschella, Francesco Jeva, Claudio Montalto, Leonardo Pignalosa

Funding This study received no specific funding. EB's salary is partially funded from the European Union's Horizon 2020 research and innovation program under the acronym ESCAPE-NET, registered under grant agreement no. 733381.

\section{Declarations}

Conflict of interest No conflict of interest to declare.

Human and animal rights statement The study was conducted in accordance with the Helsinki Declaration.

Informed consent All the patients provided informed consent for this specific study. 


\section{References}

1. Widimsky P, Wijns W, Fajadet J et al (2010) Reperfusion therapy for ST elevation acute myocardial infarction in Europe: description of the current situation in 30 countries. Eur Heart $\mathrm{J}$ 31(8):943-957. https://doi.org/10.1093/eurheartj/ehp492

2. Zijlstra F, de Boer MJ, Hoorntje J, Reiffers S, Reiber J, Suryapranata $H$ (1993) A comparison of immediate coronary angioplasty with intravenous streptokinase in acute myocardial infarction. N Engl J Med 328(10):680-684. https://doi.org/10.1056/nejm1 99303113281002

3. Terkelsen CJ, Sørensen JT, Maeng M et al (2010) System delay and mortality among patients with STEMI treated with primary percutaneous coronary intervention. JAMA J Am Med Assoc 304(7):763-771. https://doi.org/10.1001/jama.2010.1139

4. O'Connor RE, Al Ali AS, Brady WJ et al (2015) Part 9: Acute coronary syndromes: 2015 American Heart Association guidelines update for cardiopulmonary resuscitation and emergency cardiovascular care. Circulation 132(18):S483-S500. https://doi. org/10.1161/CIR.0000000000000263

5. Ibanez B, James S, Agewall S et al (2018) 2017 ESC Guidelines for the management of acute myocardial infarction in patients presenting with ST-segment elevation. Eur Heart J 39(2):119-177. https://doi.org/10.1093/eurheartj/ehx393

6. Luqman N, Sung RJ, Wang CL, Kuo CT (2007) Myocardial ischemia and ventricular fibrillation: Pathophysiology and clinical implications. Int J Cardiol 119(3):283-290. https://doi.org/10. 1016/j.ijcard.2006.09.016

7. Lettieri C, Savonitto S, De Servi S et al (2009) Emergency percutaneous coronary intervention in patients with ST-elevation myocardial infarction complicated by out-of-hospital cardiac arrest: Early and medium-term outcome. Am Heart J. https://doi.org/10. 1016/j.ahj.2008.10.018

8. Kontos MC, Scirica BM, Chen AY et al (2015) Cardiac arrest and clinical characteristics, treatments and outcomes among patients hospitalized with ST-elevation myocardial infarction in contemporary practice: a report from the National Cardiovascular Data Registry. Am Heart J 169(4):515-522.e1. https://doi.org/10. 1016/j.ahj.2015.01.010

9. O'Doherty M, Tayler DI, Quinn E, Vincent R, Chamberlain DA (1983) Five hundred patients with myocardial infarction monitored within one hour of symptoms. Br Med J 286(6375):14051408. https://doi.org/10.1136/bmj.286.6375.1405

10. Johansson I, Strömberg A, Swahn E (2004) Ambulance use in patients with acute myocardial infarction. J Cardiovasc Nurs 19(1):5-12. https://doi.org/10.1097/00005082-200401000-00004

11. Lozzi L, Carstensen S, Rasmussen H, Nelson G (2005) Why do acute myocardial infarction patients not call an ambulance? An interview with patients presenting to hospital with acute myocardial infarction symptoms. Intern Med J 35(11):668-671. https:// doi.org/10.1111/j.1445-5994.2005.00957.x

12. Mooney M, O’Brien F, McKee G, O’Donnell S, Moser D (2016) Ambulance use in acute coronary syndrome in Ireland: a crosssectional study. Eur J Cardiovasc Nurs 15(5):345-354. https://doi. org/10.1177/1474515115579134

13. Thuresson M, Jarlöv MB, Lindahl B, Svensson L, Zedigh C, Herlitz J (2008) Factors that influence the use of ambulance in acute coronary syndrome. Am Heart J 156(1):170-176. https://doi.org/ 10.1016/j.ahj.2008.01.020

14. Ma J, Wang J, Zheng W et al (2017) Usage of ambulance transport and influencing factors in acute coronary syndrome: a crosssectional study at a tertiary centre in China. BMJ Open 7(8):1-8. https://doi.org/10.1136/bmjopen-2016-015809

15. Meischke H, Ho MT, Eisenberg MS, Schaeffer SM, Larsen MP (1995) Reasons patients with chest pain delay or do not call
911. Ann Emerg Med 25(2):193-197. https://doi.org/10.1016/ S0196-0644(95)70323-3

16. Brown AL, Mann NC, Daya M et al (2000) Demographic, belief, and situational factors influencing the decision to utilize emergency medical services among chest pain patients. Circulation 102:173-178

17. Cartledge S, Finn J, Straney L et al (2017) The barriers associated with emergency medical service use for acute coronary syndrome: the awareness and influence of an Australian public mass media campaign. Emerg Med J 34(7):466-471. https://doi. org/10.1136/emermed-2016-206396

18. Chew KS, Annuar WMWM, Rahman NHNA et al (2015) A survey on the choice of transportation to come to emergency department among patients with acute coronary syndrome of a community in Malaysia. Med J Malaysia 70(1):6-11

19. Thang ND, Karlson BW, Bergman B et al (2012) Characteristics of and outcome for patients with chest pain in relation to transport by the emergency medical services in a 20 -year perspective. Am J Emerg Med 30(9):1788-1795. https://doi. org/10.1016/j.ajem.2012.02.014

20. Fares S, Zubaid M, Al-Mahmeed W et al (2011) Utilization of emergency medical services by patients with acute coronary syndromes in the Arab Gulf States. J Emerg Med 41(3):310 316. https://doi.org/10.1016/j.jemermed.2010.05.002

21. Hartford M, Karlson BW, Sjolin M, Holmberg S, Herlitz J (1993) Symptoms, thoughts, and environmental factors in suspected acute myocardial infarction. Heart Lung J Crit Care 22(1):64-70

22. Moser DK, Kimble LP, Alberts MJ et al (2006) Reducing delay in seeking treatment by patients with acute coronary syndrome and stroke: a scientific statement from the American Heart Association Council on Cardiovascular Nursing and Stroke Council. Circulation 114:168-182. https://doi.org/10.1161/CIRCULATIONAHA. 106.176040

23. Leonardi S, Montalto C, Casella G et al (2020) Clinical governance programme in patients with acute coronary syndrome: design and methodology of a quality improvement initiative. Open Heart. https://doi.org/10.1136/openhrt-2020-001415

24. Baldi E, Sechi GM, Mare C et al (2020) COVID-19 kills at home: the close relationship between the epidemic and the increase of out-of-hospital cardiac arrests. Eur Heart J 41(32):3045-3054. https://doi.org/10.1093/eurheartj/ehaa508

25. Diercks DB, Kontos MC, Chen AY et al (2009) Utilization and Impact of Pre-Hospital Electrocardiograms for Patients With Acute ST-Segment Elevation Myocardial Infarction. Data From the NCDR (National Cardiovascular Data Registry) ACTION (Acute Coronary Treatment and Intervention Outcomes Network) Registry. J Am Coll Cardiol. 53(2):161-166. https://doi.org/10. 1016/j.jacc.2008.09.030

26. Bagai A, Jollis JG, Dauerman HL et al (2013) Emergency department bypass for ST-segment-elevation myocardial infarction patients identified with a prehospital electrocardiogram: a report from the American heart association mission: Lifeline program. Circulation 128(4):352-359. https://doi.org/10.1161/CIRCU LATIONAHA.113.002339

27. Gorenek B, Lundqvist CB, Terradellas JB et al (2015) Cardiac arrhythmias in acute coronary syndromes: position paper from the joint EHRA, ACCA, and EAPCI task force. EuroIntervention 10(9):1095-1108. https://doi.org/10.4244/EIJY14M08_19

28. McKee G, Mooney M, O’Donnell S, O’Brien F, Biddle MJ, Moser DK (2013) Multivariate analysis of predictors of pre-hospital delay in acute coronary syndrome. Int J Cardiol 168(3):27062713. https://doi.org/10.1016/j.ijcard.2013.03.022

29. Bray JE, Stub D, Ngu P et al (2015) Mass media campaigns' influence on prehospital behavior for acute coronary syndromes: an evaluation of the Australian Heart Foundation's Warning Signs 
Campaign. J Am Heart Assoc. https://doi.org/10.1161/JAHA.115. 001927

30. McKinley S, Dracup K, Moser DK et al (2004) International comparison of factors associated with delay in presentation for AMI treatment. Eur J Cardiovasc Nurs 3(3):225-230. https://doi.org/ 10.1016/j.ejcnurse.2004.06.004

31. Kiguchi T, Okubo M, Nishiyama C et al (2020) Out-of-hospital cardiac arrest across the World: first report from the International Liaison Committee on Resuscitation (ILCOR). Resuscitation 152:39-49. https://doi.org/10.1016/j.resuscitation.2020.02.044

32. Lee DW, Moon HJ, Heo NH (2019) Association between ambulance response time and neurologic outcome in patients with cardiac arrest. Am J Emerg Med 37(11):1999-2003. https://doi.org/ 10.1016/j.ajem.2019.02.021

33. Greif R, Bhanji F, Bigham BL et al (2020) Education, implementation, and teams. Circulation 142(1):S222-S283. https://doi.org/ 10.1161/CIR.0000000000000896

34. Guerchicoff A, Brener SJ, Maehara A et al (2014) Impact of delay to reperfusion on reperfusion success, infarct size, and clinical outcomes in patients with St-segment elevation myocardial infarction: the INFUSE-AMI trial (INFUSE-anterior myocardial infarction). JACC Cardiovasc Interv 7(7):733-740. https://doi.org/10. 1016/j.jcin.2014.01.166
35. Fordyce CB, Al-Khalidi HR, Jollis JG et al (2017) Association of rapid care process implementation on reperfusion times across multiple ST-segment-elevation myocardial infarction networks. Circ Cardiovasc Interv. https://doi.org/10.1161/CIRCINTERV ENTIONS.116.004061

36. Stowens JC, Sonnad SS, Rosenbaum RA (2015) Using EMS dispatch to trigger STEMI alerts decreases door-to-balloon times. West J Emerg Med 16(3):472-480. https://doi.org/10.5811/westj em.2015.4.24248

37. De Rosa S, Spaccarotella C, Basso C et al (2020) Reduction of hospitalizations for myocardial infarction in Italy in the COVID19 era. Eur Heart J 41(22):2083-2088. https://doi.org/10.1093/ eurheartj/ehaa409

38. De Filippo O, D’Ascenzo F, Angelini F et al (2020) Reduced rate of hospital admissions for ACS during Covid-19 outbreak in northern Italy. N Engl J Med 383(1):1-3. https://doi.org/10.1056/ NEJMc2009166

Publisher's Note Springer Nature remains neutral with regard to jurisdictional claims in published maps and institutional affiliations. 